\title{
Bladder Outlet Obstruction by a Lymphocele following
} Kidney Transplantation

\begin{tabular}{|l|l|l|}
\hline R. & Ran & Katz $^{\mathrm{a}}$ \\
\hline E.H. & Ezekiel H. & Landau $^{\mathrm{a}}$ \\
\hline A.J. & Alon J. & Pikarsky $^{\mathrm{b}}$ \\
\hline A. & Ahmed & Eid $^{\mathrm{b}}$ \\
\hline
\end{tabular}

${ }^{\mathrm{a}}$ Departments of Urology and Surgery, and ${ }^{\mathrm{b}}$ Transplantation Unit, Hadassah Medical Center, Hebrew University, Jerusalem, Israel

\section{Key Words}

Kidney transplantation

Lymphocele

Urinary retention

\section{Abstract}

Lymphocele is a well-known complication of kidney transplantation. Patients usually present with deteriorating renal function, hydronephrosis, a nontender lower abdominal mass or ipsilateral leg edema. Urinary retention, however, is an unusual presentation of lymphocele. We herein report a case of a female patient who developed chronic urinary retention due to a pelvic lymphocele after kidney transplantation.

Ran Katz, MD, Department of Urology, Hadassah Ein Kerem Hospital, PO Box 12000, Jerusalem 91120 (Israel), Tel. +972 2 6776874, Fax+972 2 5861585, E-Mail rank@cc.huji.ac.il

\section{Case Report}

A 57-year-old female underwent living related kidney transplantation because of end-stage renal disease secondary to mesangiocapil-lary glomerulonephritis. The kidney was transplanted into the left iliac fossa. The allograft assumed immediate function and serum cre-atinine normalized within 1 week. Sonography of the kidney on the second and fourteenth days after transplantation revealed a normal flow in the renal artery, and no hydronephrosis or fluid collection was seen. The patient was discharged 2 weeks after the transplantation with a serum creatinine of 120 $\mu \mathrm{mol} / \mathrm{l}$. She returned to follow-up only 2 months after the transplantation complaining of lower abdominal discomfort and gradual swelling of her left leg. She also experienced increasing voiding difficulties including weak urinary stream and persistent urinary dribbling. Physical examination revealed suprapubic fullness and left leg edema. A neurologic examination was normal. Serum creatinine had increased to $164 \mu \mathrm{mol} / \mathrm{l}$. Sonography revealed a $16 \mathrm{~cm} \times 9 \mathrm{~cm}$ $\times 9 \mathrm{~cm}$ pelvic lymphocele away from the transplanted kidney near the bladder neck (fig. 1 ). There was mild hydronephrosis and a normal resistant index. A Foley catheter was inserted and $900 \mathrm{ml}$ of urine were evacuated. The catheter was removed, but the patient was hardly able to void and was started on a clean intermittent catheterization regimen. Postvoiding urine residuals were $450 \mathrm{ml}$ on average.

Urodynamic assessment demonstrated an abnormal urethral pressure profile with functional urethral length of $65 \mathrm{~mm}$ and maxi- 


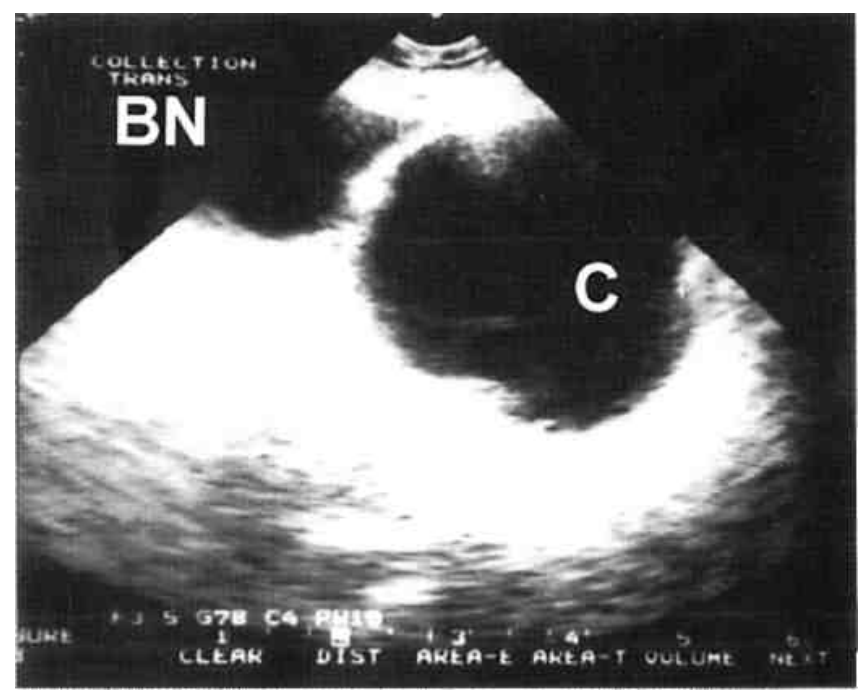

Fig. 1. Pelvic sonography. There was a $16 \mathrm{~cm} \times 9 \mathrm{~cm} \times 9 \mathrm{~cm}$ lymph collection (C) near the bladder neck $(\mathrm{BN})$.

\section{KARGEH}

E-Mail karger@karger.ch Fax + 41613061234 http://www.karger.ch

(C)1997S. KargerAG, Basel 0042-1138/97/0593-0186\$ 15.00/0

mal urethral closing pressure of $42 \mathrm{~cm} \mathrm{H20}$. A cystometrogram revealed the first desire to void at a bladder volume of $450 \mathrm{ml}$ and suprapubic pain at a volume of $705 \mathrm{ml}$ and a pressure of $30 \mathrm{~cm}$ H20. There were no involuntary contractions.

Percutaneous drainage of the lymphocele enabled marked improvement in voiding, and urine residuals decreased to 30-100 ml. Following drain removal, the patient developed urinary retention again. Sonography showed lymph re-accumulation. Surgical exploration revealed a large pelvic lymphocele behind the bladder neck, away from the transplant and inferior to the external iliac vessels. Tube drainage was performed. After the operation, the patient had no voiding difficulties. Sonography revealed no evidence of fluid collection and the postvoiding urine residual was $20 \mathrm{ml}$.

Repeat urodynamic studies demonstrated a normal urethral pressure profile with functional urethral length of $35 \mathrm{~mm}$ and maximal urethral closing pressure of $60 \mathrm{~cm} \mathrm{H20.A}$

cystometrogram showed the first desire to void at $180 \mathrm{ml}$ and suprapubic pain at $320 \mathrm{ml}$. Uroflowmetry was normal with a peak flow rate of $34.8 \mathrm{ml} / \mathrm{s}$.

Discussion

Lymphocele is a well-recognized complication of kidney transplantation with an incidence range of $0.6-18 \%$ in various series [1,2]. It may appear in the early postoperative period or years following the transplantation. Most lymphoceles are asymptomatic, clinically insignificant and resolve spontaneously. Symptomatic lympho-

celes result from an enlarging perinephric collection. Patients may present with a soft, nontender mass palpated in the lower abdomen, deterioration of renal function due to pressure on the ureter with hydronephrosis, and ipsilater-al leg edema caused by obstruction of the femoral lymphatic and venous flow. Pressure on the renal hilus may impair the renal blood flow [2, 3].

Urinary retention is an extremely rare complication of a lymphocele. In 1976, Schiff and Feldman [4] described a 36-year-old male who developed acute urinary retention 1 month after kidney transplantation due to a large para-vesical lymphocele which had displaced the bladder 
laterally. A cystourethrogram showed a normal urethra and bladder neck. The lympocele was drained surgically and voiding function returned to normal [4].

In contrast, our patient presented with a clinical picture of chronic urinary retention with overflow incontinence due to prolonged outlet obstruction as confirmed by the urodynamic studies. The altered clinical presentation was probably related to the large size as well as to the peculiar localization of the lymphocele progressively compressing the complex of the bladder neck and urethra. To our knowledge, this is the first case of chronic urinary retention due to bladder outlet obstruction caused by a lymphocele following kidney transplantation.

\section{References}

Bry J, Hull D, Bartus SA, Schwiezer RT: Treatment of recurrent lymphocele following renal transplantation. Transplantation 1990;49: 477-480.

Gilliland DJ, Spies JB, Brown SB, Yrizarry JM, Greenwood LH: Lymphoceles: Percutaneous treatment with povidone-iodine sclerosis. Radiology 1989;171:227-229.

Starzl TE, Groth CG, Putnum CW: Urological complications in 216 human recipients of renal transplantation. Ann Surg 1970;172:1-22. Schiff M, Feldman RA: Lymphocele following renal transplantation: An unusual cause of urinary retention. BrJUrol 1976;48:122.

Outlet Obstruction by Lymphocele

Urollnt 1997;59:186-187

187 